Sabit ortodontik tedavide beslenme değişikliği ve kilo kaybı

\section{Weight loss in fixed orthodontic treatment}

Geliş tarihi: 23 Kasım 2020

Kabul tarihi: 26 Kasım 2020

doi: 10.5505/yeditepe.2021.07742

\section{Yazışma adresi:}

Dr. Öğr. Üyesi Refika Topal

Sakarya Üniversitesi Diş Hekimliği Fakültesi, Ortodonti Anabilim Dalı Mithatpaşa Mahallesi Adnan Menderes Caddesi No:122/B

Adapazarı / Sakarya

Tel: 05068535992

E-posta: refikatopal@hotmail.com

\section{ÖZET}

Amaç: Bu çalışmanın amacl, sabit ortodontik tedavinin ilk ayında hastalarda meydana gelebilecek beslenme alışkanlıkları ve buna bağlı olarak kilo değişikliklerini değerlendirmektir. Gereç ve Yöntem: Çalışma yaş ortalaması 23ะ1,5 olan 105 hasta (45 kadın, 60 erkek) ile yüz yüze araştırmacı tarafından yapılan bir anket çalışmasıdır. Çalışmada sabit ortodontik tedaviye başladıktan bir ay sonra kontrol seansında cinsiyet ve yaşa göre yeme alışkanlıklarının değişimi ve kilo kaybı ilişkisi değerlendirilmiştir. Analizlerde Fisher Exact ve Pearson Ki-kare testleri kullanımıştır.

Bulgular: Sabit ortodontik tedavide $(\% 82,1)$ bireyde yeme alışkanlığı değişmesi ile birlikte kilo kaybının gözlendiği ve istatistiksel olarak anlamlı olduğu tespit edilmiştir $(p<0.001)$. Erkeklerde sabit ortodontik tedavide yeme alışkanlığını değişimi ile ortodontik tedavide kilo kaybı gözlenenler bireyler $(\% 76,3)$ istatistiksel olarak anlamlı düzeyde daha fazla olduğu gözlendi $(p<0.001)$. Kadınlarda da sabit ortodontik tedavide yeme alışkanlığını değişimi ile ortodonti tedavide kilo kaybı gözlenen bireyler $(\% 89,7)$ istatistiksel olarak anlamlı düzeyde daha fazla olduğu gözlendi $(p<0.001)$.

Sonuç: Sabit ortodontik tedavinin başlangıç ayında bireylerde yeme alışkanlıklarının değişimi ile birlikte kilo kaybı gerçekleşmektedir.

Anahtar kelimeler: Sabit ortodontik tedavi, kilo kaybı, beslenme değişikliği.

\section{ABSTRACT}

Aim: The aim of this study is to evaluate the weight changes that may occur in patients in the first month of fixed orthodontic treatment.

Materials and Methods: The study is a questionnaire study conducted by a face-to-face researcher with 105 patients (45 females, 60 males) with an average age of $23 \pm 1.5$. One month after starting fixed orthodontic treatment, the relationship between eating habits and weight loss was evaluated in the control session according to gender and age. Fisher Exact and Pearson Chi-square tests were used in the analysis.

Results: In fixed orthodontic treatment (82.1\%), it was found that weight loss was observed and statistically significant with the change of eating habits in the individual $(p<0.001)$. It was observed that, in males with constant orthodontic treatment, eating habits change and orthodontic treatment weight loss (76.3\%) were statistically significantly higher $(p<0.001)$. It was observed that in females, with the change of eating habits in orthodontic treatment, weight loss was observed in orthodontic treatment $(89.7 \%)(p<0.001)$.

Conclusion: In the initial month of fixed orthodontic treatment, weight loss occurs with the change of eating habits in individuals.

Key words: Fixed orthodontic treatment, weight loss, dietary habits change. 


\section{GíRiş}

Genellikle yüz ve dental estetiği iyileştirmek için hastalar ortodontik tedavi arayışına girmektedir.' Son zamanlarda hastalar daha yüksek estetik algıya sahip olmakla birlikte ortodontik tedavi talebinde artış gözlenmektedir. ${ }^{2}$ Sabit ortodontik tedavide bireysel farklılıkla birlikte bazı hastalarda rahatsızlık hissi görülebilmektedir. ${ }^{3-5}$ Sabit ortodontik tedavilerde, braketlerden dolayı yeme güçlüğü, dişlerde ağrı, ağız içi yumuşak dokularda ülserasyon, telaffuz problemi gibi zorluklar yaşamaktadır. Bu zorluklar bireylerde yaşam kalitelerini etkileyebilmektedir. ${ }^{6}$ Braketlerden ve dişlerin hareketi sonucu meydana gelen ağrı sebebiyle sert besinleri çiğneme ve yutma hastalar için zor olabilmektedir.7 Ayn zamanda ortodontik tedavide braketlerin ısırma ve çiğneme sırasında dişten ayrılma riskini önlemek için de yumuşak bir diyet önerilmektedir. Hastaların sert, yapışkan tarzda çiğnenebilir yiyecekler tüketilmesine izin verilmez..$^{5,8,9}$ Braketler dişlere yerleştirildikten sonra ilk 24 saat içerisinde çiğneme yeteneğinde azalma görülmektedir. Bununla birlikte, 4 ile 6 hafta arasında çiğneme yeteneğinin tedaviden önceki seviyesine dönmesi beklenmektedir.7 Hastalara ağrı ve rahatsızlık hissini azaltmak amacıyla yumuşak ve küçük parçalı gıdalar tüketilmesi önerilmektedir. Bu durum rutindeki beslenme alışkanlığının değişmesine sebep olmaktadır. ${ }^{9}$

Çalışmalar ortodontik tedavinin hastaların günlük yaşam rutinlerinde beslenme alışkanlıklarını değiştirebileceği veya kısıtlayacağı potansiyel bir etkiye sahip olduğu belirtmektedir. ${ }^{10}$ Sabit ortodontik tedavinin hastaların kilosu ve diyet alımı üzerindeki etkileri halen daha fazla araştırma gerektirmektedir. ${ }^{11}$ Ortodontik tedavi, hastaların beslenmesinde değişikliklere neden olurken fiziksel, fizyolojik ve duygusal streslere de neden olmaktadır. ${ }^{12}$ Ortodontik tedavi, bir kişinin diyetinin devamlılığını, kalitesini ve miktarını değiştirebilmektedir. ${ }^{13,14}$ Lee ve ark, ${ }^{15}$ ağız içi ülserasyonlar ve dişlerde ağrının gıda alımının kısıtlanmasına neden olabileceğini ve bunun sonucunda beslenme bozukluğunun ve istemeden kilo kaybının gözlenebileceğini belirtmiştir.Ortodontik tedaviler genellikle uzun sürelidir. Bundan ötürü ortodontistler hastalarının genel sağlık durumunu gözleme imkanına sahip olmaktadır. Fiziksel değişimleri gözlemlenebilmektedir. Bunun yanında hastalar her randevuya geldiğinde rutin olarak hastaların ağırlık ölçülmesi yapılmamaktadır. ${ }^{16}$

Sabit ortodontik tedavilerde diyet alışkanlıkları ve besinlerin tüketim şekli değişikliğinden dolayı hastalarda beslenme alışkanlığındaki sert değişiklikten ötürü kilo kaybı meydana gelebilmektedir. ${ }^{17,18}$ Sabit ortodontik tedavi hastalarına, tedavinin devamlılığı ve başarısı açısından braketlerin diş yüzeylerinden ayrımasını önlemek amacıyla diyet değişikliği önerilmektedir. Aynı zamanda tedavinin başlangıç günlerinde ve ilk ayında hastalar tarafından yoğun bir şekilde dişlerde meydana gelen ağrılardan kay- naklı beslenme alışkanlıklarının belirgin değişiklik gösterdiği ortodonti klinik pratiğinin sıklıkla gündeminde bulunmaktadır. Her iki durum birlikte gözlemlenince beslenme alışkanlığı değişikliğinin ve bu durumun hastalarda kilo kaybına sebep olup olmadığını değerlendirmek amacıyla çalışmada, sabit ortodontik tedavinin ilk ayında hastalarda beslenme alışkanlıkları değişimini ve meydana gelebilecek kilo değişiklikleri değerlendirilmiştir. Bu çalışmanın hipotezi hastalarda beslenme alışkanlığı değişimine bağlı olarak kilo kaybı gözlemlenmeyeceğidir.

\section{GEREÇ VE YÖNTEM}

Bu çalışma Sakarya Üniversitesi Diş hekimliği Fakültesi Ortodonti Kliniği'nde ortodontik tedavi olmak amacıyla gelen ve sabit ortodontik tedavisine başlanacak yaş ortalaması 23 $\pm 1,5$ olan 105 birey (45 kadın, 60 erkek) ile yapılan anket çalışmasıdır. Çalışma izni Sakarya Üniversitesi Tıp Fakütesi Etik Kurulu 71522473/050.01.04/410 sayılı onayı ile yapılmıştır. Çalışma esnasında Helsinki Deklarasyonu ilkelerine uyularak gerekli hasta onamları alınmıştır. Çalışmaya katılım gönüllük esasına göre belirlenmiş olup, katılım oranı \%100'dür. Daimi dişlenmesi tamamlanmış, daha önce ortodontik tedavi görmemiş, 12 yaş üzerindeki, sabit ortodontik tedavi intiyacı olan bireyler çalışmaya dahil edilmiştir. Besleme alışkanlığında herhangi bir diyet uygulayan, beslenme problemi olan, mide ameliyatı geçiren, zihinsel engeli olan, fonksiyonel tedavi ve /veya maksiller ekspansiyon planlaması olan hastalar çalışmaya dahil edilmemiştir. Bütün hastalara sabit ortodontik tedavi planlaması yapılmıştır. Hastalara tedaviye başlanacağı günde braketlerin diş yüzeylerinden ayrılamaması için dikkat etmesi gereken beslenme kuralları hakkında bilgilendirilmiştir. Hastalara yumuşak ve küçük parçalar halinde beslenme önerilip kurallara uymaları gerektiği belirtilmiştir. Sert kabuklu kuru yemiş (fındık, fıstık, leblebi), sert meyve (elma, yeşil erik), sert sebze(havuç), kızarmış ekmek, patlamış mısır, sert ve kemikli et tüketilmemesi gerektiği belirtilmiştir. Bir ay sonraki kontrole geldiklerinde kilo değişimi hakkında soru içeren anket yapılacağı konusunda hastalar bilgilendirilmiştir. Ortodontik tedavi başlangıcında bütün bireylere hem maksiller hem mandibular arka 0.022" slot Roth (Mini Master Series, American Orthodontics, Sheboygan, Wisconsin, USA) braketler yerleştirildikten sonra, $0.014 \mathrm{NITI}$ (American Orthodontics, Sheboygan, Wisconsin, USA) konvansiyonel ark teli yerleştirilerek sabit ortodontik tedavilere başlanmıştır. Bütün bireyler kontrol için tedavi başladıktan 1 ay sonra kontrol seansına geldiklerinde anket formu yöneltilmiştir. Anket formu araştırmacı R.T. tarafından yüz yüze görüşme yöntemi ile klinikte hastalarla birlikte dolduruldu. Anket formunda hastalara dört soru yönletildi. Birinci soru yaş, ikinci soru cinsiyet, şeklinde kişisel bilgiler yer aldı. Üçüncü soruda 'Ortodontik tedaviye başladıktan sonra yeme içme alışkanlıklarınızda değişiklik gerçekleşti mi?' ve dör- 
düncü soruda 'Ortodontik tedaviye başladıktan sonra kilo kaybınız gerçekleşti mi? soruları soruldu.

\section{İstatistiksel Analiz}

Kategorik ölçüm düzeyindeki değişkenin birbirleri ile ilişkileri Fisher Exact ve Pearson Ki-kare testleri ile analiz edilmiştir. Tanımlayıcı istatistik olarak sayısal değişkenler için sayı ve \% değerleri verilmiştir. İstatistiksel analizler için SPSS Windows version 23.0 paket programı kullanılmış ve $p<0.05$ istatistiksel olarak anlamlı kabul edilmiştir.

\section{BULGULAR}

Tablo 1' de yeme alışkanlığı değişimi demografik özelliklerin ilişkisi Pearson Ki-kare testi ile analiz verileri sunulmaktadır.

Tablo 1. Ortodontik tedavide yeme alışkanlığı değişimi ve kilo kaybının değer lendirilmesi.

\begin{tabular}{|c|c|c|c|c|c|c|c|c|}
\hline & \multicolumn{4}{|c|}{ Yeme alışkanlığı değişimi } & \multicolumn{4}{|c|}{ Kilo kaybı } \\
\hline & Evet & Hayır & Toplam & $\mathbf{p}$ & Evet & Hayır & Toplam & $\mathrm{P}$ \\
\hline $\begin{array}{l}\text { Yas } \\
\text { grupları } \\
\text { n(\%) }\end{array}$ & & & & 0.311 & & & & 0.170 \\
\hline $12-22$ & $36(53.7)$ & $25(65.8)$ & $61(58.0)$ & & $32(50.8)$ & $29(69.0)$ & $61(58.0)$ & \\
\hline 23-32 & $17(25.4)$ & $5(13.2)$ & $22(21.0)$ & & $16(25.4)$ & $6(14.3)$ & $22(21.0)$ & \\
\hline $33-42$ & $14(20.9)$ & $8(21.1)$ & $22(21.0)$ & & $15(23.8)$ & $7(16.7)$ & $22(21.0)$ & \\
\hline $\begin{array}{l}\text { Cinsiyet } \\
\mathbf{n}(\%)\end{array}$ & & & & 0.907 & & & & 0.227 \\
\hline Kadın & $29(43.3)$ & $16(42.1)$ & $45(42.9)$ & & $33(52.4)$ & $27(64.3)$ & $60(57.1)$ & \\
\hline Erkek & $38(56.7)$ & $22(57.9)$ & $60(57.1)$ & & $30(47.6)$ & $15(35.7)$ & $45(42.8)$ & \\
\hline
\end{tabular}

Yeme alışkanlığı değişiminin olan ve olmayan bireyler yaş gruplarına ayrılarak kıyaslandığında gruplar arası istatistiksel olarak anlamlı farklıık tespit edilmedi( $p>0,05)$. Aynı zamanda kilo kaybı olan ve olmayan bireylerde yaş grupları arasında istatistiksel anlamlı farklılık görülmedi $(p>0,05)$. Tablo 1'de erkekler ve kadınlarda yeme alışkanlığı değişen ve değişmeyen bireyler arasında istatistiksel olarak anlamlı farklılık bulunmadı ( $p>0.05$ ). Yine erkekler ve kadınlarda kilo kaybı gözlenen ve gözlenmeyen bireyler arasında istatistiksel anlamlı farklılık bulunmadı $(p>0,05)$.

Tablo 2. Ortodontik tedavide yeme alışkanlığı değişiminin tüm bireylerde kilo kaybı ile ilişkisi.

\begin{tabular}{|c|c|c|c|c|}
\hline \multicolumn{5}{|c|}{ Ortodontik tedavide yeme alışkanlığı değişimi } \\
\hline \multicolumn{5}{|c|}{$\begin{array}{l}\text { Ortodontik tedavide kilo kaybı n (\%) } \\
<0.001\end{array}$} \\
\hline Evet & $55(82.1)$ & $8(21.1)$ & $63(60.0)$ & \\
\hline Hayır & $12(17.9)$ & $30(78.9)$ & $42(40.0)$ & \\
\hline
\end{tabular}

Tablo 2'de Pearson Ki-kare testi ile analizde ortodontik tedavide $(\% 82,1)$ bireyde yeme alışkanlığı değişmesi ile birlikte kilo kaybının gözlendiği ve istatistiksel olarak anlamlı olduğu tespit edildi $(p<0,001)$. Ortodontik tedavide yeme alışkanlığı değişmeyen bireylerde de $(\% 21,1)$ kilo kaybı meydana geldiği gözlendi $(p<0,001)$.

Tablo 3'de cinsiyetler kendi grupları içinde yeme alışkanlıklarının değişmesinin kilo kaybı ile olan ilişkisini değerlendirmek için Fisher Exact ile analiz edilmiş veriler sunulmaktadır.
Tablo 3. Cinsiyetlere göre yeme alışkanlığının değişip değiş̧memesinin kilo kaybı ile olan ilișkisi.

\begin{tabular}{|c|c|c|c|c|}
\hline & & Ortodontil & vide yeme & lığımm değisşimi \\
\hline & & Evet & Hayır & $\mathbf{P}$ \\
\hline & Ortod & vide kilo ka & & $<0.001$ \\
\hline Kadın & Evet & $29(76,3)$ & $4(18,2)$ & \\
\hline & Hayır & $9(23,7)$ & $18(81,8)$ & \\
\hline & Ortod & vide kilo kay & & $<0.001$ \\
\hline Erkek & Evet & $26(89,7)$ & $4(25,0)$ & \\
\hline & Hayır & $3(10,3)$ & $12(75,0)$ & \\
\hline
\end{tabular}

Erkeklerde sabit ortodontik tedavide yeme alışkanlığını değişimi ile ortodontik tedavide kilo kaybı gözlenenler bireyler $(\% 76,3)$ istatistiksel olarak ortodontik tedavide yeme alışkanlığı değişen kilo kaybı olmayan bireylerin oranına $(\% 23,7)$ kıyasla anlamlı düzeyde daha fazla olduğu gözlendi $(p<0,001)$. Kadınlarda da sabit ortodontik tedavide yeme alışkanlığını değişimi ile ortodonti tedavide kilo kaybı gözlenen bireyler $(\% 89,7)$ ortodontik tedavide yeme alışkanlığı değişmeyen kilo kaybı gözlenen bireyler (\%25), yeme alışkanlığı değişip kilo kaybı gözlenmeyen $(\% 10,3)$ bireyler arasında istatistiksel olarak anlamlı düzeyde daha fazla olduğu gözlendi $(p<0,001)$.

\section{TARTIŞMA}

Sabit ortodontik tedavide diyet alışkanlıklarındaki değişimleri ve buna bağlı olarak bireylerde kilo değişimlerini değerlendiren pek çok çalışma mevcuttur.,5,19 Çalışmada hastalarda beslenme alışkanlığı değişimine bağlı olarak kilo kaybı gerçekleşmeyeceği hipotezi reddedilmiştir.

Bu çalışmada ortodontik tedaviye başladıktan sonra yaş grupları arasında yeme alışkanlıklarında değişim gösteren ve göstermeyen hastalarda istatistiksel olarak anlamlı farklıık tespit edilmemiştir. Daha önce yapılan bir çalışmada ortodontik tedavinin fiziksel, fizyolojik ve duygusal bir stres yarattığı ve bunun da bireyin beslenme gereksinimlerini arttırarak beslenme alışkanlıklarında değişime ve besin tüketiminin artırdığı belirtilmektedir. ${ }^{12}$ Bunun yanı sıra, ortodontik tedavi sırasında dişlerin hareket etmesinden dolayı genellikle çiğneme zorluğu ile karşılaşıldığı ve braketlerin kırılma riskine karşı yumuşak yiyecekler ve küçük parçalar halinde tüketim şekli ile önceki beslenme alışkanlıklarının değiştiği belirtilmektedir. ${ }^{20-22}$ Önceki çaıışmalar ile bu çalışmada farkııı̆ın oluşmasının nedeninin bireyler arasında farklı yaş grupları ve sosyokültürel faktörlerden kaynaklanabileceği düşünülmektedir.

Kadın ve erkek hastalarda tedaviye başladıktan sonra beslenme alışkanlıklarında değişiklik gösteren ve beslenme alışkanlıklarında değişim göstermeyenler arasında istatistiksel olarak anlamlı farklıık gözlenmemiştir. Ortodontik tedavide diyet alışkanlıklarını değerlendiren bir çaıışmada ise bireyler tedaviye başladıktan sonra özellikle başlangıç dönemlerinde dişlerdeki ağrilardan ötürü sert besinler tüketemediklerini ve ortodontist tarafından braketlerin kırılmaması için verilen talimatlara uygun beslen- 
me şeklini oluşturduklarını böylelikle diyet programlarının öncesinden çok farklı olduğunu belirtmektedirler. ${ }^{23}$

Bu çalışmada yeme alışkanlığı değişen bireylerde gözlenen kilo kaybı istatistiksel olarak anlamlı olduğu tespit edildi. Ajwa ve ark., ortodontik tedavide başlamadan önce ve tedavi başlangıcından bir ay sonra bireylerdeki anlamlı düzeyde kilo kaybının meydana geldiğini belirtmektedir. Bu durumun beslenme alışkanlıklarının değişmesi ve dişlerde ortodontik tedaviden kaynaklı ağrılardan dolayı yeme konforunun bozulmasından kaynaklandığını belirtmektedirler. Ortodontik tedavide ilk ziyaretinden ikinci ziyaretine kadar kilo kaybı meydana geldiği belirtilmektedir. ${ }^{19}$

Çalışmada hem kadınlarda hem erkeklerde tedavi başlangıcından sonra yeme içme alışkanlığı değişmesine bağlı olarak kilo kaybı gözlendiği tespit edilmiştir. Sandeep ve ark., ortodontik tedavi gören çalışma grubunun hem erkeklerde hem de kadınlarında ağırlık değişiklikleri olduğunu belirtmektedir. Aktif ortodontik tedavinin ilk 1 aylık döneminde belirgin bir ağırlık azalması olduğu belirtmektedir. Tedavi devamında 1 . ay ve 3 . ay zaman dilimleri arasında hem kadınlarda hem erkeklerde ağırlıklarında artış gözlendiği belirtilmektedir. Ancak 3. ayın sonunda bireylerde başlangıç kilolarına dönülmediği ve aradaki kilo farklarının istatistiksel olarak anlamlı farklılık oluşturmadığı belirtilmektedir. ${ }^{9}$ Dara ve Sayar, sabit ortodontik tedavi uyguladıkları hastalarında tedavi başlangıcındaki kilo değerlerinin birinci hafta ve birinci ay sonrasında başlangıç kilolarına göre anlamlı düzeyde azalma meydana geldiğini belirtmektedirler. ${ }^{5}$ Bu farklıı̆ın beslenme alışkanlıklarında ani değişimle açıklayarak sert besinleri tüketilmemesi ve küçük parçalar halinde besinleri tüketmelerinden kaynaklandığını belirtmektedirler.

Çalışmada hem kadınlarda hem erkeklerde kilo kaybı gözlenirken bu durum istatistiksel olarak anlamlı farklılık oluşturmamıştır. Ajwa ve ark. ${ }^{19}$ da hem kadınlarda hem de erkeklerde ilk ayda kilo kaybı gözlenirken kilo kaybı gerçekleştiğini ancak arasındaki farkın istatistiksel olarak anlamlı olmadığı belirtilmektedir. Sandeep ve ark., ${ }^{9}$ erkeklerde ilk ay içindeki kilo kaybı istatistiksel olarak kadınlara göre daha yüksek olduğu belirtilmektedir.Cinsiyetler arasındaki gıda önceliğindeki farklııkların, vücut ağırığı beslenme içeriğine bağlı olduğu için kilo kaybında veya tekrar kilo alımında değişiklikler göstermesi mümkün olabileceği düşünülmektedir.

Çalışmada günümüzde ortodonti klinik pratiğinde uzun süreli takip gerektiren sabit ortodontik tedavi hastalarına yaklaşımımızda beslenme alışkanlığı değişimi ve tedavi ilk ayındaki hastalarda braketlere adaptasyon sürecinde meydana gelebilecek hassasiyetten ötürü diyet değişimi ile kilo kaybının genel sağlık durumunu olumsuz yönde etkilememesi için daha dikkatli davranılması gerektiği vurgulanmak istenmektedir. Aynı zamanda gelecekte sabit ortodontik tedavi yapılacak bireylerde kilo değişiminin uzun dönem takibi ile gerçekleşen çalışmaların yapılması ile birlikte farklı sonuçlar elde edilebileceği düşünülmektedir.

\section{SONUÇ}

Sabit ortodontik tedavinin başlangıç ayında bireylerde yeme alışkanlıklarının değişimi ile birlikte kilo kaybı gerçekleşmektedir.

\section{KAYNAKLAR}

1. Borzabadi-Farahani, A. An insight into four orthodontic treatment need indices. Progress in orthodontics 2011; 12:132-142.

2. Oliveira PG, Tavares RR, Freitas JC. Assessment of motivation, expectations and satisfaction of adult patients submitted to orthodontic treatment. Dental press journal of orthodontics 2013; 18:81-87.

3. Marques LS, Paiva SM, Vieira-Andrade RG, Pereira LJ, Ramos-Jorge ML. Discomfort associated with fixed orthodontic appliances: determinant factors and influence on quality of life. Dental press journal of orthodontics 2014; 19:102-107.

4. Krishnan V. Orthodontic pain: from causes to management a review. Eur J Orthod 2007; 29: 170-179.

5. Kılınç DD, Sayar G. Assessment of weight loss in the first three months of fixed orthodontic treatment. Selcuk Dent J 2019; 6: 18-22.

6. Haslinda R, Azrul H. Esthetic consideration in conjunction with periodontic and orthodontic approaches in Class III gingival recession: A case report. World Applied Sciences Journal 2014; 30:365-369.

7. Feldmann I, List T, Bondemark L. Orthodontic anchoring techniques and its influence on pain, discomfort, and jaw function a randomized controlled trial. The European Journal of Orthodontics 2011; 34:102-108.

8. Carter LA, Geldenhuys M, Moynihan PJ, Slater DR, Exley $C E$, et al. The impact of orthodontic appliances on eating-young people's views and experiences. J Orthod 2015; 42: 114-122.

9. Sandeep KS, Singaraju GS, Reddy VK, Mandava P, Bhavikati VN, et al. Evaluation of body weight, body mass index, and body fat percentage changes in early stages of fixed orthodontic therapy. Journal of International Society of Preventive \& Community Dentistry 2016; 6: 349-358.

10. Scheurer PA, Firestone AR, Bürgin W B. Perception of pain as a result of orthodontic treatment with fixed appliances. The European Journal of Orthodontics 1996; 18: 349-357.

11. Johal A, Al Jawad FA, Marcenes W, Croft N. Does orthodontic treatment harm children's diets? J Dent 2013; 41: 949-954.

12. Ajmera AJ, Tarvade SS, Patni VR. A systematic nutritional and dietary guideline for orthodontic patients. Journal of Orthodontic Research 2015; 3:88-91. 
13. Riordan DJ. Effects of orthodontic treatment on nutrient intake. Am J Orthod Dentofacial Orthop 1997; 111: 554-561.

14. Schmitz KE, Liles $S$, Hyman AN, Hofstetter CR, Obayashi $S$, et al. Youth receiving orthodontic care are not immune to poor diet and overweight: a call for dental providers to participate in prevention efforts. Pediatr Dimens 2016; 1: 59-64.

15. Lee JY, Kim SW, Kim JM, Shin IS, Yoon JS. Two Cases of Eating Disorders in Adolescents with Dental Braces Fitted Prior to the Onset of Anorexia Nervosa. Psychiatry Investig 2015; 12: 411-414.

16. Hedayati Z, Khalafinejad F. Relationship between body mass index, skeletal maturation and dental development in 6-to 15-year old orthodontic patients in a sample of Iranian population. Journal of Dentistry 2014; 15: 180186.

17. Feras AAJ, Susan JC, Nick C, Ama J. A qualitative study of the early effects of fixed orthodontic treatment on dietary intake and behaviour in adolescent patients. European Journal of Orthodontics 2012; 34:432-436.

18. Hafiz A, Jamal A, Azura N, Sahudi R, Nor MM. The impact of fixed appliances (braces) on Quality of life. J Int Dent Med Res 2019;12: 650-654.

19. Ajwa N, Makhdoum L, Alkhateeb $H$, Alsaadoun A, Alqutub $S$, et al. The Impact of Orthodontic Appliance on Body Weight Changes, Dietary Habits, and Self-Perceived Discomfort in Early Stages of Orthodontic Treatment. Global J Health Science 2018; 10: 11-17.

20. Farzanegan F, Zebarjad SM, Alizadeh S, Ahrari F. Pain reduction after initial in archwire placement orthodontic patients: A randomized clinical trial. Am J Orthod Dentofacial Orthop 2012;141: 169-173.

21. Krukemeyer $A M$, Arruda $A O$, Inglehart MR. Pain and Orthodontic Treatment. Angle Orthod 2009;79: 11751181.

22. Kolenda J, Fischer-Brandies $H$, Ciesielski R, Koos B. Oral health related quality of life after orthodontic treatment for anterior tooth alignment: Association with emotional state and sociodemographic factors. J Orofac Orthop 2016; 77:138-145.

23. Abed Al Jawad F, Cunningham SJ, Croft N, Johal A. A qualitative study of the early effects of fixed orthodontic treatment on dietary intake and behaviour in adolescent patients. The European Journal of Orthodontics 2011; 34: 432-436. 